\title{
Editorial
}

\section{El Derecho frente a la pandemia por COVID-19}

\author{
Por: Martín Risso Ferrand, Graciela Ruocco, Beatriz Ramos Cabanellas, Gabriel \\ Valentín, Leonardo Slinger, Leonardo Costa, Cristina Herdt, Diego Gamarra, \\ Walter Guerra, María Paula Garat
}

Una nueva Revista de Derecho se presenta en esta edición, con muy buenos trabajos de doctrina que abordan aspectos trascendentes en distintas áreas del Derecho. Sin embargo, esta edición se vio también implicada en el hecho de mayor significancia actual: la pandemia por COVID-19.

La situación que originó el coronavirus mostró y demostró aspectos que versan sobre muchas áreas: lo sanitario, el cuidado de la salud, aspectos económicos, abordajes psicológicos, nuevas modalidades de trabajo, distintos protocolos, entre tantos otros. También puso en evidencia la importancia de la investigación científica en todas esas áreas, no siendo el Derecho ajeno a ello.

En los últimos días y en medio de esta pandemia hemos visto de los más variados análisis sobre su efecto en el Derecho y para el Derecho. Desde las consecuencias de la feria judicial extraordinaria, la suspensión de plazos, las garantías; pero también los límites a las libertades, la protección de datos personales y sensibles, las implicancias del teletrabajo para el Derecho Laboral, y, especialmente, las consecuencias que esta pandemia puede aparejar para las empresas, para las familias, en la violencia o para los sectores más vulnerables.

Asimismo, los Gobiernos adoptaron distintas medidas económicas y fiscales para hacer frente a las consecuencias financieras que esta situación apareja. 
Desde la Revista de Derecho, y desde nuestro compromiso con la investigación en Derecho, nos vimos inmiscuidos con esta particular situación y ello se tradujo en esta editorial. Invitamos a algunos Profesores y Profesoras de la Facultad de Derecho de la Universidad Católica del Uruguay (UCU) a reflexionar sobre el impacto que esta pandemia apareja en las diversas áreas del Derecho.

El resultado, que lo observarán a continuación, son distintas perspectivas que conllevan a una reflexión conjunta: el Derecho no es ajeno a esta pandemia, y la investigación de estas distintas consecuencias se hace más que necesaria.

Junto con agradecerles a los colaboradores, invitamos a los lectores a reflexionar con nosotros y a aportar, desde nuestro lugar en la academia, a este análisis de una situación inesperada y por demás compleja, pero que sin dudas nos aparejará distintos aprendizajes que aunarán en un mayor desarrollo del Derecho.

Dra. María Paula Garat

Editora científica de la Revista de Derecho Universidad Católica del Uruguay, Montevideo, Uruguay Correspondencia: maria.garat@ucu.edu.uy 


\section{El COVID-19 y el Derecho Constitucional}

\section{Prof. Martín Risso Ferrand}

La Constitución uruguaya, en una regulación mayoritariamente proveniente de 1830, prevé tres situaciones que pueden admitir el ejercicio de poderes de emergencia: los casos graves e imprevistos de ataque exterior o conmoción interior, el caso extraordinario de traición o conspiración contra la patria y el estado de guerra. Asimismo, para estas situaciones especiales, la Carta prevé cuáles son los poderes de emergencia que pueden ser ejercidos. No es la solución habitual en el derecho comparado en que se suele incluir la noción de emergencia o urgencia, con mayor amplitud.

Lo anterior podría ser un problema para Uruguay ya que si la pandemia no llega a constituir una conmoción interior grave e imprevista no podría ejercerse ningún poder de emergencia. De todas formas, y en este caso, la cuestión no es grave ya que existen normas legales que permiten superar la cuestión sin recurrir al ejercicio de poderes de emergencia en términos constitucionales. Veamos.

La libertad física de las personas puede limitarse, en situaciones de normalidad, en dos casos: a) por razones penales o criminales y b) por otros motivos. Respecto al primer caso, la Constitución dispone que un sujeto puede ser arrestado en caso de flagrante delito o con semiplena prueba y orden del juez competente, o un Juez puede disponer la detención o prisión preventiva de un acusado, o se puede estar ante la figura del condenado por sentencia ejecutoriada. En ningún otro caso, por motivos penales, puede privarse de la libertad a un individuo en períodos de normalidad.

Pero fuera de los temas penales, la privación de la libertad cuenta solo con la regulación genérica del artículo 7 de la Constitución respecto a la limitación de la protección en el goce de la libertad. Más preciso es el inciso 3 del artículo 22 de la Convención Americana que prevé que la libertad de circulación puede ser restringida por ley en la medida indispensable en una sociedad democrática, para prevenir infracciones penales o para proteger ... la salud pública o los derechos y libertades de los demás. $\mathrm{O}$ sea, fuera del ámbito penal, ley mediante, puede limitarse la libertad de circulación, entre otros casos, para proteger la salud pública. 
¿Qué prevé nuestro ordenamiento legal para los casos de epidemias o peligros para la salud pública? Básicamente se debe recurrir a la ley 9.202 y de ella surge:

El Ministerio de Salud Pública tiene, entre otros cometidos, la adopción de todas las medidas que estime necesario para mantener la salud colectiva, y su ejecución por el personal a sus órdenes, dictando todos los reglamentos y disposiciones necesarios para ese fin primordial.

En caso de epidemia o de serias amenazas de invasión de enfermedades infectocontagiosas el Ministerio adoptará de inmediato las medidas conducentes a mantener indemne el país o disminuir los estragos de la infección.

En el caso anterior, el Poder Ejecutivo dispondrá la intervención de la fuerza pública para garantir el fiel cumplimiento de las medidas dictadas.

El Ministerio, además y cuando fuere necesario, podrá disponer el aislamiento y detención de las personas que por sus condiciones de salud pudieran constituir un peligro colectivo.

Asimismo, todo habitante tiene la obligación de someterse a las medidas profilácticas o de asistencia que se le impongan cuando su estado de salud pueda constituir un peligro público.

El Ministerio de Salud Pública podrá imponer la denuncia y tratamiento obligatorio de las afecciones que puedan tener una repercusión sobre la sociedad.

También se prevé que puede disponerse el aislamiento o la internación en un establecimiento o lugar determinado.

El Ministerio de Salud Pública podrá disponer la clausura de cualquier establecimiento en caso de infracción grave de las normas vigentes en materia de salud.

Entiendo que lo anterior constituye todo el elenco de atribuciones y poderes jurídicos suficiente para enfrentar la epidemia.

Solo veo dos temas dudosos en la ley. El primero, refiere a las sanciones administrativas que frente a infracciones a la normativa pueda corresponder, pues la ley prevé multas, pero el monto máximo sería \$ 500. La ley es del año 1934 por lo que considerando la pérdida de ceros de nuestra moneda hoy en día la multa máxima sería de $\$ u$ a 0,00 . . Frente a esta situación caben dos soluciones. La más práctica, sería procurar actualizar dicho tope por IPC y ver en cuánto quedaría el tope de la multa. La otra sería aprobar una ley de un artículo que establezca el tope en unidades reajustables o unidades indexadas. 
Otra cuestión, ingresando en un tema claramente constitucional, es la participación del juez como garantía ineludible de los derechos humanos y la comunicación a familiares y conocidos de toda persona cuya libertad sea limitada. Pese a que la ley 9.202 no refiere a esto, aplicando directamente la Constitución y la Convención Americana, los propios reglamentos del Poder Ejecutivo pueden disponer que toda restricción de la libertad de un sujeto por razones sanitarias, cuando sea urgente la limitación, debe ser puesta en conocimiento inmediato de un juez y debe permitirse al aislado comunicar a sus allegados la situación en forma inmediata. Es más, tratándose de una restricción a la libertad de circulación por razones no penales, debería permitirse que el sujeto mantenga en su poder y use su teléfono celular.

Por último, respecto a la posible utilización de medidas prontas de seguridad (artículo 168 numeral 17 de la Constitución), debe repararse que estas medidas proceden en los "casos graves e imprevistos" de ataque exterior o conmoción interior. La clave, y prescindo de otros aspectos complejos, está en determinar qué significa "grave". Por supuesto que la interpretación no puede ser subjetiva pues cada uno podrá valorar una situación como grave o no grave. Por el contrario, esta expresión refiere a una situación que no pueda ser superada por las disposiciones previstas en el orden jurídico para períodos de normalidad (lo que no excluye que pueda haber situaciones complejas). Si las autoridades pueden encarar su acción para superar el problema actuando dentro de la Constitución y de la ley, la situación no será grave en los términos de este numeral 17 y no procederán las medidas prontas de seguridad. Pienso entonces que las medidas prontas de seguridad no proceden pues las previsiones legales en materia de epidemias son suficientes y, si por excepción, se requiriera algún ajuste legal, el Poder Legislativo en nuestros tiempos, puede aprobar leyes en el día, por lo que no hay forma de encontrar algo que quede fuera del ordenamiento jurídico regular.

Tampoco se puede recurrir a la suspensión de la seguridad individual (artículo 31 de la Constitución) pues esto solo es posible en los casos de traición o conspiración contra la patria $\mathrm{y}$, aun adhiriendo a teorías conspirativas, no podría considerarse a esta disposición como aplicable a este caso de epidemia.

En definitiva, entiendo que, para enfrentar la epidemia, aun cuando se deba aumentar la intensidad de las medidas, se tiene respaldo suficiente en el orden legal que impedirán la adopción de medidas prontas de seguridad. 


\section{EI COVID-19 y el Derecho Administrativo}

\section{Prof. Graciela Ruocco}

La disminución, el enlentecimiento y —en algunos casos — la paralización de la producción, importación y comercialización de bienes y prestación de servicios que supone el combate a la pandemia por COVID-19 en el mundo, ha generado enormes dificultades.

En lo que al Derecho Administrativo refiere numerosos impactos pueden advertirse. Sólo a vía de ejemplo queda en evidencia los inconvenientes que pueden suscitarse en la ejecución de contratos de toda naturaleza, en particular los contratos públicos. Ello impone un estudio de los mecanismos contractuales y normativos que permitan proteger a la parte que se ha visto dificultada o impedida de cumplir con sus obligaciones, atendiendo a las particularidades de su régimen jurídico y al fin último que dichos contratos persiguen: la satisfacción del interés público.

La Declaración de Estado de Emergencia Nacional Sanitaria en Uruguay como consecuencia de la pandemia por COVID-19, dispuesta por Decreto del Poder Ejecutivo $\mathrm{N}^{\circ}$ 93/020, de 13 de marzo de 2020, ha generado un aluvión normativo de gran importancia.

En algunos países, como España, una gran parte de toda esa normativa ha sido dedicada a la contratación pública.

No ha ocurrido así en Uruguay, razón por la cual el marco normativo aplicable en la materia, resulta del Texto Ordenado de Contabilidad y Administración Financiera (TOCAF) que recoge el conjunto de normas legales que regulan la contratación pública, sin perjuicio de los Pliegos de Condiciones Generales y Particulares, así como los términos de los propios contratos.

En materia de contratación pública, la situación de emergencia sanitaria afecta dos grandes bloques:

- por un lado, la ejecución de los contratos en vigor y los procedimientos de contratación en marcha, y 
- por otro, las licitaciones y contratos que se generen luego de la Declaración, para atender la situación de emergencia.

Una de las medidas más relevantes incluidas en el RD 463/2020 español es la suspensión de los plazos de tramitación de todos los procedimientos de las entidades del sector público, lo que no ha ocurrido en Uruguay.

De manera que, respecto del primer bloque que presentamos, será necesario resolver las alteraciones en la ejecución de los contratos públicos vigentes, así como la tramitación de los procedimientos de selección ya iniciados a la luz del marco normativo vigente y los principios generales y los específicos aplicables en la materia.

Tampoco se han dictado normas específicas para regular las contrataciones que sean imprescindibles durante el estado de emergencia sanitaria, razón por la cual también será aplicable la normativa resultante del TOCAF, que prevé algunos supuestos de excepción al principio general que impone la selección del contratista del Estado mediante procedimientos competitivos, habilitando la contratación directa.

En otro orden, cabe mencionar la multiplicidad de restricciones a los derechos fundamentales que pueden generarse en virtud de las medidas adoptadas. Sólo a vía de ejemplo cabe mencionar la prohibición de espectáculos públicos, las limitaciones de ingreso de pasajeros al país, la suspensión de clases en los centros de enseñanza, el cierre temporal de establecimientos turísticos, la creación del Impuesto destinado al Fondo COVID-19, la postergación de las elecciones departamentales, entre muchos otros.

Todo lo cual hará necesario un intenso control a cargo de los órganos competentes, así como asegurar la transparencia en la actuación administrativa, en orden a defender y garantizar el respeto de aquellos derechos que puedan verse afectados.

Porque el Estado de Derecho no está en cuarentena, y por ello debemos seguir luchando contra las inmunidades del poder. 


\section{El COVID-19 y el Derecho de Familia}

\section{Prof. Beatriz Ramos Cabanellas}

Tanto la pandemia en sí misma como las medidas adoptadas por el gobierno (hechos del príncipe) dejaron en evidencia qué asuntos son esenciales para las personas. Es por ello que, temas tales como los alimentos, la inserción familiar de menores de edad, el régimen de comunicación (visitas) y la violencia de género y doméstica, entre otros, marcaron la agenda sustancial del derecho de familia y pusieron a prueba las Instituciones existentes.

Dada la brevedad solicitada, destacaremos en estas líneas el tema de "los alimentos" no sólo por su fundamento (el derecho a la vida y la solidaridad familiar), sino por la necesidad de su efectivo y rápido cumplimiento.

En el particular contexto que ha generado la pandemia y como consecuencia de la misma la situación de los sujetos de la obligación alimentaria (deudor y acreedor) puede haber cambiado en forma drástica.

Así, el deudor puede haber pasado al seguro de paro (situación muy frecuente en la actualidad) o sencillamente haber perdido su trabajo mientras que el acreedor puede haber logrado un trabajo circunstancial debido a que la oferta laboral requiere personas con menor riesgo de contraer el virus o sencillamente es beneficiario de alguno de los planes de emergencia dispuestos para el período de emergencia sanitaria.

Martha Nussbaum ${ }^{1}$, una de las pensadoras más reconocidas de nuestro tiempo, manifestó: "ahora tenemos un tiempo para pensar que no esperábamos tener, debemos aprovecharlo" porque esta crisis podrá ser "un tiempo de aprendizaje y resolución"

En esta línea y respecto al tema de "alimentos", de importancia por la cantidad de reclamaciones realizadas ante el foro, nos deberíamos plantear si las normas existentes son suficientes y adecuadas frente a estas situaciones de emergencia teniendo presente que podrían repetirse situaciones similares en el futuro.

\footnotetext{
${ }^{1}$ Alconada Mon, H. (26 de abril de 2020). Coronavirus. Martha Nussbaum: "Esta pandemia es una gran oportunidad para abrir nuestras vidas a las realidades de otros". La Nación. Recuperado de https://www.lanacion.com.ar/el-mundo/coronavirus-martha-nussbaum-esta-pandemia-es-grannid2358443
} 
Se observa que algunas de las normas existentes dieron respuesta a las necesidades requeridas, mientras que en otros casos parecería adecuado analizar su eventual modificación.

Entre las primeras se encuentra la ley N. ${ }^{\circ} 19480$ de enero de 2017 por la que se creó un Registro de Personas obligadas al pago de pensiones alimenticias a cargo del Banco de Previsión Social que tuvo por finalidad asegurar el cumplimiento del servicio pensionario a favor de niños y adolescentes.

En base a la existencia del Registro creado por dicha ley, durante la emergencia sanitaria en el Poder Judicial se dictó la Circular 56/2020 por la que se comunicó que "las pensiones alimenticias cautelares, provisorias o definitivas que servían obligados alimentarios por retención de su salario serán descontadas, cuando corresponda, de los seguros de desempleo que beneficien al deudor de alimentos".

Es decir, que la finalidad de la norma pudo cumplirse durante la emergencia en la medida que la existencia del Registro y las acciones de los jueces de familia agilitaron el cobro efectivo de los alimentos.

Entre las disposiciones que podría analizarse su eventual modificación se encontrarían las que refieren al orden y número de integrantes de la familia obligados a servir alimentos. Al respecto, debemos tener presente que existe un deber de solidaridad y asistencia familiar dispuesto en el artículo 45 CNA y que en la medida en que se amplíe el número de familiares obligados a servir alimentos el Estado podría contar con mayores recursos para atender a los integrantes más vulnerables de la sociedad que carecen de familia. 


\section{EI COVID-19 y el Derecho Procesal}

\section{Prof. Gabriel Valentín}

La propagación del virus SARS-Cov-2 y la enfermedad asociada COVID-19 ${ }^{1}$, que desde el 11 de marzo de 2020 es calificada por la OMS como una pandemia ${ }^{2}$, determinó la aparición de diversas respuestas de los gobiernos. En particular, en el caso de los sistemas de justicia, la respuesta casi automática de casi todos ellos fue la suspensión del servicio judicial y de los plazos procesales, con una atención mínima para casos urgentes ${ }^{3}$.

En nuestro país, la Suprema Corte de Justicia y el Tribunal de lo Contencioso declararon la existencia de una feria extraordinaria y la suspensión de plazos y actuaciones programadas, sin perjuicio de la posibilidad de habilitar días inhábiles en casos que corriera grave riesgo el ejercicio de los derechos.

En grandes líneas, la propagación del virus y la enfermedad, y las medidas inicialmente adoptadas por los sistemas de justicia pusieron en el centro del debate la posible afectación de principios generales y procesales básicos.

Por una parte, las grandes dificultades para ejercitar plenamente los derechos y la incertidumbre acerca de la situación de derechos cuyos plazos de caducidad o prescripción podían vencer en el período de actividad casi totalmente suspendida generaron una grave afectación de la seguridad jurídica.

Por otra parte, la paralización casi total supuso una importante afectación a los principios de universalidad de acceso al proceso y tutela jurisdiccional efectiva. Ese extraordinario estado de situación dejó al descubierto algo que era impensable en el grado actual de evolución de los sistemas de justicia: que la efectividad de las promesas

\footnotetext{
${ }^{1}$ V. información estadística actualizada a diario de la Johns Hopkins University (JHU): https://gisanddata.maps.arcgis.com/apps/opsdashboard/index.html\#/bda7594740fd40299423467b48e9ecf 6. Para América, v. información de la Pan American Health Organization: https://who.maps.arcgis.com/apps/webappviewer/index.html?id=2203b04c3a5f486685a15482a0d97a87\& extent $=-17277700.8881 \% 2 \mathrm{C}-1043174.5225 \% 2 \mathrm{C}-1770156.5897 \% 2 \mathrm{C} 6979655.9663 \% 2 \mathrm{C} 102100$.

${ }^{2}$ V.: https://www.paho.org/es/tag/enfermedad-por-coronavirus- COVID-19.

${ }^{3}$ V. Arellano, J., Cora, L., García, C. y Sucunza, M. (2020, mayo). Estado de la Justicia en América Latina bajo el COVID-19. CEJA, p. 92.

http://biblioteca.cejamericas.org/bitstream/handle/2015/5648/REPORTECEJA_EstadodelajusticiaenALba joel COVID19_20mayo2020.pdf?sequence=5\&isAllowed=y.
} 
constitucionales podía verse seriamente afectada, y que esa afectación podía ser generalizada.

Adicionalmente, el "parate" de la actividad jurisdiccional dejó en claro que a pesar de que las TIC nos ofrecen instrumentos eficientes para mejorar la prestación del servicio los sistemas judiciales no habían aprovechado esas amplísimas posibilidades. Esto provocó que en casi todos los sistemas los poderes judiciales se lanzaran casi "sin red" al uso de las TIC para realizar actividades procesales. Lo cual tiene, por cierto, un aspecto indudablemente positivo - ya que en pocas semanas se empezaron a aplicar herramientas que llevan años de desarrollo-, pero otra parte enfrentó a los operadores a importantes desafíos para no afectar otros principios básicos y muy caros a la idea de proceso.

En el caso uruguayo, el Colegio de Abogados del Uruguay elaboró dos proyectos dirigidos a abordar algunos de esos problemas: uno, destinado a regular la "Feria jurisdiccional extraordinaria y suspensión de plazos", y otro, sobre "Utilización de tecnologías de la información y comunicación en procesos jurisdiccionales”.

Ambos proyectos tomaron estado parlamentario, pero a la fecha solo se aprobó el destinado a para regular la feria extraordinaria y la suspensión de plazos (ley 19.879, de 30 de abril de 2020). El referido a la regulación de las TIC sigue a estudio del parlamento, en la Comisión de Constitución, Códigos, Legislación General y Administración de la Cámara de Representantes ${ }^{4}$.

Por otra parte, la Suprema Corte de Justicia y el Poder Judicial reglamentaron la salida de la feria y la primera empezó a adoptar algunas medidas para avanzar en la implementación de las TIC.

Aún queda mucho por hacer para la normalización de los sistemas, en el plano normativo, de gestión y prácticas de los operadores. Pero también mucho que aprender de las lecciones que esta extraordinaria situación nos deja.

\footnotetext{
4 “Procesos jurisdiccionales. Utilización de tecnologías de la información y comunicación”, C/138/20. Rep. 41.
} 


\section{El COVID-19 y el Derecho Laboral Aspectos laborales de la emergencia sanitaria}

\section{Prof. Leonardo Slinger}

La emergencia sanitaria generada por el COVID-19 generó consecuencias inmediatas en el normal desarrollo del trabajo. Tanto desde el Poder Ejecutivo, a través del Ministerio de Trabajo, como en forma directa por los propios actores sociales se adoptaron medidas para adaptar el trabajo a la situación de emergencia.

En primer lugar, la pandemia precipitó el teletrabajo. Si bien ello no es un fenómeno nuevo en el mercado de trabajo, la emergencia determinó que la mayoría de las empresas decidieran que pasaran a trabajar desde el domicilio todos aquellos trabajadores que en función de las tareas a su cargo pudieran hacerlo. De este modo, por la fuerza de los hechos se impuso una modalidad de trabajo que hasta ahora era poco desarrollada, y de la que muchos actores sociales tenían dudas de su viabilidad.

Por su parte, el Poder Ejecutivo contribuyó a su implementación exhortando su realización a través de la Resolución 94/2020. La referida resolución dispuso que el empleador debe suministrar los implementos necesarios para realizar la tarea encomendada y que la realización del teletrabajo deberá ser comunicada a la Inspección General de Trabajo y Seguridad Social para su control.

El sistema también se habilitó para las empresas amparadas en el sistema de Zonas Francas, que de regla se encuentran obligadas a realizar su actividad exclusivamente desde territorio franco. Lo que implicó una flexibilización de la regulación del trabajo en zonas francas que hasta ese momento nunca había sido permitido por la administración.

Asimismo, para contemplar la dificultad de dar trabajo de parte de las empresas desde el Poder Ejecutivo se adoptaron decisiones que tienen todas un fin último, cual es, el de mantener las fuentes de trabajo. Entre ellas destacamos la posibilidad de adelantar licencias y los cambios en el régimen de seguro de paro.

Como es sabido, la licencia debe gozarse al año siguiente en que se genera. Sin embargo, por resolución del 20 de marzo de 2020 se permitió que mediando acuerdo entre trabajador y empleador se puede adelantar el goce de las licencias que cada empleado generará a lo largo del 2020. 
Por otra parte, Poder Ejecutivo flexibilizó el régimen de seguro de desempleo, habilitando el seguro de paro parcial para los trabajadores mensuales. Figura que hasta el presente solo existía para los trabajadores jornaleros. Esta nueva modalidad permite que a lo largo del mes el trabajador preste tareas algunos días, y pase al seguro por el resto de los días del mes, percibiendo el respectivo subsidio.

Desde la seguridad social también se alentaron soluciones para la situación de excepción, disponiéndose que los mayores de 65 años pueden permanecer temporalmente en aislamiento percibiendo durante el período el subsidio de enfermedad. La gran novedad a este respecto es que este amparo no requiere certificación médica, sino que es una opción que se da a estas personas para que individualmente decidan si quieren hacer uso del beneficio.

Por su parte, como se dijo antes, en el ámbito privado las partes también alcanzaron acuerdos para contemplar la nueva realidad laboral. Así se han celebrado diversos acuerdos novatorios previendo reducciones temporales de salario y horario, o acuerdos de rebaja salarial con pago de despido parcial.

También en varias empresas se acordó el adelantamiento de licencias de años anteriores que los trabajadores tenían agendadas para más adelante en el año. Y se alcanzaron acuerdos de licencias especiales sin goce de sueldo. En esta línea puede citarse el acuerdo alcanzado el nivel de la industria de la construcción, por el que se creó una licencia extraordinaria sin goce de sueldo desde el 24 de marzo al 5 de abril, con el pago de una partida extraordinaria.

En definitiva, la situación de emergencia sanitaria hizo generar soluciones creativas desde distintos ámbitos (Poder Ejecutivo, seguridad social, actores sociales) para adaptar el trabajo a la necesidad de "quedarse en casa" y para reducir el impacto negativo que la baja de trabajo podía inmediatamente generar en el mercado de empleo; y demostró la madurez de trabajadores y empleadores para buscar soluciones tendientes a proteger los puestos de trabajo de la mayor forma posible. 


\section{El COVID-19 y el Derecho Financiero \\ Las medidas prudentes asumidas por el Uruguay para mantener los motores de la economía andando}

\section{Prof. Leonardo Costa}

La pandemia ocasionada por el COVID-19 y las medidas de confinamiento voluntario, generaron para la economía en general y para las finanzas públicas un fuerte desafío. La caída en la economía nacional golpeada por el cierre de comercios y servicios trajo aparejado una disminución en el consumo, en ventas, en ingresos de los hogares y la pérdida — al menos en forma temporal — de puestos de trabajo. A su vez, para el Estado se produjo una inevitable caída en sus ingresos tributarios e ingresos no tributarios provenientes de las empresas públicas, lo que generaron un shock negativo en las finanzas públicas. Por el contrario, la decisión del Gobierno de proteger a los sectores más golpeados mediante flexibilización del seguro por desempleo, seguido de la creación de mecanismos paliativos para sectores informales, trajeron el consiguiente aumento del gasto público. A todo esto, cabe destacar la clara respuesta de las autoridades sanitarias por mantener, y aumentar la cobertura, y el sistema nacional de salud.

Vale decir que la tarea de controlar el déficit fiscal —más castigado aún por la pandemia - planteado por el Gobierno entrante se vio postergada, al menos en forma temporal, por un aumento del gasto público, razonable desde nuestro punto de vista, y una disminución consecuente de los ingresos públicos generada por la caída de la actividad económica.

Frente a la dificultad planteada, las autoridades decidieron - a diferencia de otros países de la región - ser anticíclicos y por ende se procuró mantener "los motores encendidos de la economía", apelando a algunas medidas económicas que se relacionaron con un aumento en el acceso del crédito al sector privado. En tal sentido se aprobaron medidas económicas que tuvieron como objetivo contribuir a la liquidez de la economía de manera de preservar la cadena de pagos. Se establecieron líneas de créditos especiales en el Banco República, se aumentó el fondo de garantía de la Agencia Nacional de Desarrollo (ANDE) para otorgar créditos por un monto de hasta 2.500 millones de 
dólares. Se creó un programa de una línea de crédito directo de ANDE con una tasa subsidiada por el Ministerio de Economía y Finanzas.

Por otra parte, se aprobó una autorización para bancos, empresas de servicios financieros y empresas administradoras de crédito de mayores activos, para extender los plazos de vencimiento de los créditos - por hasta 180 días - que dichas entidades hubiesen otorgado a personas físicas o empresas del sector no financiero (familias, unipersonales, PYMES entre otros, principalmente vinculadas al sector industrial y comercial). En el caso de préstamos amortizables al consumo, se autorizó trasladar el pago de cuotas por varios meses. La mencionada autorización tuvo por objetivo la atención de la situación de familias y empresas, frente a las restricciones financieras inesperadas por pérdida temporaria de ingresos a consecuencia de la coyuntura provocada por las medidas tomadas por la prevención de propagación del coronavirus (COVID-19).

En adición, en materia fiscal, se estableció una postergación del pago de impuestos para pequeños empresarios ("Literal E"), así como un aplazamiento en los pagos de las cuotas otorgadas. Para empresas monotributistas, unipersonales y sociedades personales de hasta 10 empleados en régimen de aportación industria y comercio, se subsidiaron y financiaron aportes patronales de los dueños y socios de sociedades personales al Banco de Previsión Social (BPS).

Sin perjuicio de esta última medida fiscal, el mayor cambio tributario, y quizás la mayor señal de austeridad emitida por el Poder Ejecutivo, fue la iniciativa de la creación del Impuesto a la Emergencia Sanitaria COVID-19 y de un Adicional al Impuesto a la Asistencia de la Seguridad Social, aprobado finalmente por la Ley 19.874 de 8/4/2020.

El Impuesto Emergencia Sanitaria COVID-19 resulta ser un impuesto a los ingresos mensuales de personas físicas, que grava la totalidad de las remuneraciones y prestaciones nominales, en efectivo o en especie, derivadas de servicios personales prestados al Estado, Gobiernos Departamentales, Entes Autónomos y Servicios Descentralizados, personas de derecho público no estatal y entidades de propiedad estatal en las que el Estado o cualquier entidad pública posea participación mayoritaria, cualquiera sea la naturaleza jurídica de la relación de dependencia, correspondientes a los ingresos devengados correspondientes a los meses de abril y mayo de 2020, excluyéndose del impuesto el sueldo anual complementario y de corresponder el salario vacacional. Cabe destacar que se autorizó al Poder Ejecutivo a prorrogar su aplicación hasta por un periodo máximo de dos meses, dando cuenta a la Asamblea General. 
El impuesto resulta ser un impuesto progresivo por clase, es decir que la tasa correspondiente al tramo gravado se aplica a todo el ingreso, como lo que ocurre en los impuestos proporcionales. Los ingresos nominales gravados son a partir de los $\$ 120.000$, a los cuales se les aplicarían tasas que van del 5 al 20\%. Por su parte, para el caso de las remuneraciones de cargos políticos, de particular confianza, y funcionarios públicos que desempeñan tareas en el exterior o representan al país en Comisiones Binacionales, el ingreso se encuentra gravado en su totalidad por una tasa del $20 \%$.

A su vez se creó un adicional al Impuesto a la Asistencia de la Seguridad Social que grava los ingresos correspondientes a las jubilaciones, pensiones y prestaciones de pasividad similares, servidos por instituciones públicas y privadas, residentes en la República. Los ingresos gravados serían de \$120.000 en adelante, a los cuales se les aplicaría tasas de 5 al $20 \%$.

La respuesta del Gobierno a la pandemia fue pues a mi juicio pragmática y claramente anticíclica, es decir aumentar focalizadamente el gasto y mantener a la vez la economía andando. Es de esperar que la salida, merced al manejo prudente del gasto público, seguida de medidas claras de protección a la regla de derecho y respeto a los contratos, hagan esperar un aumento de la confianza de los inversores que sirva para que la salida sea más rápida de lo esperado. 


\section{El COVID-19 y el Derecho Comercial}

\section{Prof. Cristina Herdt}

El mundo enfrenta una crisis sanitaria sin precedentes, con efectos sociales y económicos cuyos alcances aún no es posible predecir. Los problemas económicos impactan y seguirán influyendo en el ámbito jurídico. El impacto generalizado del COVID-19 sobre las diversas actividades económicas, impone breves comentarios sobre sus posibles efectos sobre los actos, negocios y relaciones jurídicas regulados por el derecho comercial. Las personas físicas y jurídicas que realizan actividad comercial y/o empresarial, así como todos aquellos que celebran contratos comerciales o realizan actos regulados por el derecho comercial, de una manera u otra se han visto o se verán afectados por los efectos negativos causados por la pandemia. La reducción drástica de las actividades económicas, la paralización o reducción de la producción y/o comercialización y ventas, genera un efecto negativo en cadena o dominó que afecta el cumplimiento de las obligaciones asumidas, desestabiliza el equilibrio económicofinanciero de las empresas, comerciantes, contratantes o simples obligados, y en muchos casos provocará la insolvencia de aquéllos. Una cuestión intrínsecamente relacionada es la relativa a si ello puede considerarse de acuerdo al actual marco legal, una razón de "causa extraña no imputable" (fuerza mayor o caso fortuito), y si configura o no una causal de justificación del incumplimiento, exonerando de responsabilidad al deudor.

Podemos distinguir por lo menos tres situaciones: a) efectos sobre los contratos; b) efectos sobre obligaciones derivadas de títulos valores de contenido dinerario; c) efectos en materia concursal.

En relación a los contratos comerciales: cabe destacar que rige el principio de que los contratos legalmente celebrados son ley para las partes: artículo 209 del Código de Comercio; y además, que en forma mayoritaria la doctrina y la jurisprudencia, han rechazado la doctrina de la revisión del contrato por excesiva onerosidad superviniente. También deben tomarse en consideración los artículos 219 y 220 del citado Código.

De acuerdo al artículo 219, el deudor debe indemnizar los daños y perjuicios por su incumplimiento, salvo causa extraña que no le es imputable. El artículo 220 por su 
parte establece "No se deben daños y perjuicios, cuando el deudor no ha podido dar o hacer la cosa a que estaba obligado, o ha hecho lo que le estaba prohibido, cediendo a fuerza mayor, o por caso fortuito..."; luego, el citado artículo expresamente excluye los casos que no están comprendidos en dicha regla: "1 ${ }^{\circ} \mathrm{Si}$ alguna de las partes ha tomado sobre sí especialmente los casos fortuitos, o la fuerza mayor. $2^{\circ} \mathrm{Si}$ el caso fortuito ha sido precedido de alguna culpa suya, sin la cual no habría tenido lugar la pérdida o inejecución. $3^{\text {o }} \mathrm{Si}$ el deudor había caído en mora antes de realizarse el caso fortuito, no comprendiéndose en esta excepción el caso en que la cosa habría perecido del mismo modo, en manos del acreedor". La causa extraña no imputable es una eximente de responsabilidad. Producido el incumplimiento, si éste tuvo como causa un hecho externo, imprevisible e irresistible, y dicho hecho generó una imposibilidad de cumplimiento para el obligado; dicho incumplimiento no genera la responsabilidad del deudor.

La pandemia puede ser considerada una causa extraña no imputable al deudor, siempre que cumpla con las exigencias legales para configurar una eximente de responsabilidad. Los efectos del COVID-19 no pueden considerarse "per se" una razón que justifique el incumplimiento de los contratos comerciales. Por tanto, siempre que se pueda cumplir la prestación a la que se obligó el deudor, el obligado debe cumplir sin poder excusarse en la existencia de causa de fuerza mayor. Si en cambio, el incumplimiento tiene como causa directa la pandemia, y existe nexo de causalidad con el suceso ocurrido, el incumplimiento no podrá dar lugar a indemnización de los daños y perjuicios.

Por tanto, la pandemia podrá o no ser una causa de fuerza mayor, debiendo analizarse en cada caso concreto el contrato en cuestión, qué se pactó con respecto a las razones de fuerza mayor y si la obligación u obligaciones incumplidas efectivamente fueron incumplidas como consecuencia directa de aquella causa. En definitiva, el COVID-19 no altera la normativa vigente en materia de cumplimiento e incumplimiento de los contratos, sino que según los casos, podrá o no configurar una causa de fuerza mayor eximente de responsabilidad, debiendo en tal caso acreditarse o probarse por quien la invoca, su configuración y nexo causal en relación a la obligación incumplida, esto es; que constituye una circunstancia que no pudo ser prevista ni evitada que imposibilita absolutamente para el cumplimiento de la obligación de que se trate. 
Para los contratos a celebrarse en el futuro, es prudente que las partes regulen de manera adecuada los efectos de esta situación en las obligaciones que contraigan. Pueden incluir como causa de fuerza mayor las limitaciones causadas por efectos puntuales causados por el COVID-19, por ejemplo, suspensión del transporte y/o cierre de fronteras.

\section{En relación a las obligaciones derivadas de títulos valores de contenido}

dinerario: la situación de dificultades económicas y de crisis generada en muchos sectores de actividad como consecuencia del COVID-19, demuestra el considerable aumento de los incumplimientos (definitivos y por retardo) en la cadena de pagos. Asimismo, la proliferación de títulos valores, plantea la necesidad de abordar la temática desde la perspectiva de la normativa específica que regula a los vales, las letras de cambio y los cheques. En este ámbito la normativa aplicable se encuentra en el artículo 108 del Decreto-Ley No. 14.701 y el artículo 45 de la Ley 14.412, que enumeran las excepciones que se pueden oponer en el juicio ejecutivo cambiario. Ninguna de dichas normas prevé las razones de fuerza mayor o caso fortuito como posibles eximentes de responsabilidad de los obligados cambiarios ni como causa que impida el progreso del juicio ejecutivo.

Respecto al ámbito concursal: es de esperar el incremento de los procesos concursales, derivados de la situación de insolvencia de personas físicas o jurídicas, comerciantes o no, afectadas por la situación general de reducción y enlentecimiento de las actividades económicas a nivel nacional, regional y mundial. En este ámbito no existe normativa específica en materia de causas de fuerza mayor o caso fortuito. Por lo tanto, producida la insolvencia, de conformidad a la Ley No. 18.387, procede la declaración del concurso. Si el concurso se produce como consecuencia directa del COVID-19, esto es, de los efectos económicos perjudiciales generados por la nueva realidad económica, y si además, no se configuran presunciones absolutas o relativas de culpabilidad, seguramente el concurso será calificado de fortuito.

Los precedentes son escasos comentarios a una problemática compleja y sin precedentes, pero cuya instalación en nuestro sistema jurídico es incuestionable. Por ello, para llegar a conclusiones adecuadas en cuanto a los efectos del COVID-19 en el Derecho Comercial, se requiere de un análisis individual de cada situación, contrato, negocio jurídico y obligación comercial que esté en juego. 


\section{EI COVID-19 y el Sistema Democrático}

\section{Prof. Diego Gamarra}

La situación de reclusión y distanciamiento social generada a partir de la aparición de casos de portadores de COVID-19 en Uruguay, así como las medidas jurídicas propiamente restrictivas de la libertad y de exhortación adoptadas en tal sentido, por razones de salud pública, presentan diferentes aspectos que merecen atención desde el punto de vista del funcionamiento del sistema democrático. Son muchos los impactos, las interrogantes e incluso las posibilidades que se vienen generando $\mathrm{y}$, como si no fuese suficiente el nivel de complejidad en lo sanitario y social, debe considerarse que el virus también es "contagioso" para la economía.

Bajo el vasto eje trazado es posible considerar no pocos temas de interés. Conviene destacar entre ellos el novedoso recurso a la exhortación estatal como prescripción en sentido amplio, una revaloración de la cosa pública y de las relaciones de cooperación, cierto interés en la propuesta de cuño republicano de instauración de una renta básica universal, el tratamiento de las situaciones de emergencia bajo la Constitución uruguaya y el relacionamiento de los Poderes en escenarios extraordinarios.

Por su necesaria vinculación con el concepto de democracia, cabe aunque sea mencionar también algunos problemas de delimitación y restricción de derechos $-v . g r$. de la libertad, de la privacidad y del derecho de reunión-, y la reafirmación de la necesidad de atender a nuevas expresiones o manifestaciones de su ejercicio, especialmente de los de participación política en sentido amplio, como resultado de la disponibilidad de nuevas herramientas tecnológicas.

En otro orden de ideas, por un lado, el fenómeno ha requerido la solución con celeridad de cuestiones jurídicas muy puntuales, como determinar mecanismos alternativos de funcionamiento adecuado de distintas autoridades públicas o la postergación de las elecciones departamentales y municipales.

Por otro lado, se han dirigido las miradas también a repensar asuntos de más largo aliento, como el diseño de la esfera pública internacional de decisiones colectivas, para 
abordar con mayor legitimidad y eficacia problemas — como una pandemia a nivel mundial— que aquejan a la humanidad como tal.

En fin, en una breve nota editorial sobre un tema tan fecundo, se puede hacer poca cosa más que presentar algunos puntos como invitaciones para posteriores desarrollos. De todas formas, para finalizar, quisiera apuntar dos observaciones adicionales y, a partir de ellas, respectivamente, indicar una oportunidad y formular una precaución.

La primera observación consiste en la notable precipitación de la discusión de temas que estaban en la agenda - en virtud de interpelaciones provocadas por las innovaciones-, pero que fue necesario comenzar a considerar más intensamente antes de lo pensado.

Existe por tanto una oportunidad para valerse del impulso y explorar nuevas soluciones a problemas viejos — como el de la distribución de la riqueza y el acceso a una ciudadanía en condiciones materiales adecuadas-, o adelantarse ante problemas inminentes o relativamente nuevos, como el uso de las tecnologías en la prestación de servicios públicos, las posibles pérdidas de empleo, la necesidad de una deliberación libre e igualitaria en el mundo digital, o el rediseño de instituciones que den respuesta moral y técnicamente justificada ante nuevas afrontas que trascienden fronteras - como las resultantes de epidemias o de agresiones al ambiente-.

La segunda observación consiste en la exaltación de algunos rasgos negativos en el juego institucional que se vienen perfilando desde hace buen tiempo. Sin dudas el Poder Ejecutivo se presentó como el protagonista en el manejo de la emergencia, pero a tal punto que parecen haber faltado a la escena los otros actores.

En cierto punto es razonable la centralización en la toma de decisiones en momentos de emergencia, para dar respuestas con prontitud. Pero ello en lo absoluto significa que los otros Poderes puedan desentenderse ${ }^{1}$, más bien todo lo contrario, su intervención y control devienen todavía más relevantes. Especialmente si se tiene en cuenta que la base legal de la actuación administrativa es en la especie el artículo 2 de la ley $N^{\circ} 9.202$ del año 1934, una disposición considerablemente antigua.

\footnotetext{
${ }^{1}$ Nótese que en la Constitución no se prevén poderes especiales del Poder Ejecutivo en una situación como la generada, pues definitivamente no aplican por su objeto las medidas previstas en el artículo 31 y es francamente difícil sostener la aplicabilidad de las previstas en el 168 numeral 17. La solución constitucional no es otra que la general en materia de delimitación de la libertad y de derechos, se requiere a tales efectos de ley en sentido orgánico formal y la concurrencia de razones de interés general.
} 
Ello no merece reproches jurídicos, pero particularmente expone la ausencia de una apreciación política actual por parte del Poder Legislativo y una débil cooperación entre Poderes.

Así, resta para culminar presentar la anunciada precaución. A un cierto desbalance en el diseño constitucional en beneficio del Poder Ejecutivo y en particular del Presidente de la República, se le añade desde hace tiempo un mayor calado desde la práctica política. Debe cuidarse que la exaltación circunstancial no se consolide en una profundización de los desequilibrios de poder, siempre enemigos de la libertad. 


\section{El COVID-19 y el Sistema de Justicia}

\section{Prof. Walter Guerra}

La pandemia declarada por la Organización Mundial de la Salud (OMS) el 11 de marzo de 2020 a raíz de la acción del COVID-19 ha provocado una verdadera conmoción a nivel global. Nuestro país no ha estado ajeno a las consecuencias y los altos costos que la misma apareja en diversos ámbitos, a las alteraciones al funcionamiento del Estado.

El servicio de justicia estatal de nuestro país debió ajustar su actividad compatibilizándola con la propia seguridad sanitaria de sus funcionarios y prestatarios del servicio. Tanto la Suprema Corte de Justicia como el Tribunal de lo Contencioso Administrativo en el ámbito de sus respectivas competencias, dispusieron feria judicial sanitaria la cual concluyó el día 15 de mayo de 2020 sin llegar a paralizar el servicio, manteniéndolo bajo régimen especial de feria judicial. La Suprema Corte Justicia por Resolución No. 33/2020 ha dispuesto una serie de medidas para retomar la actividad de diferente tipo, y el inicio de un plan piloto para la realización de audiencias por videoconferencia en los términos previstos en el art. 11 de dicha Resolución sirviéndose del auxilio de la tecnología, aspecto éste que antes del COVID-19 ya se avizoraba en nuestra legislación (Ley 18.237) y en la reglamentación (Acordadas 7405, 7637, 7644 y 7648).

Más allá de una primera impresión negativa, es necesario cambiar la visión del fenómeno encarándolo como una oportunidad, utilizando el tiempo en el que nos quedamos en casa para reflexionar en esa dirección. De ello extraemos la observación que los tiempos de todos los acaecimientos, y sobre todo los que afectan derechos, se han acortado extraordinariamente al igual que los cambios.

Este sacudón recibido nos obliga a ir incluso más allá de las medidas circunstanciales adoptadas, necesarias por supuesto para hacer frente a la actividad derivada de los requerimientos que el servicio exige. Nos demuestra que, dada la nueva realidad del mundo actual, un virus (el evento puede ser de otro tipo) no necesitó más de tres semanas para trascender, algo más de dos meses para ser declarada "pandemia", en tanto que medidas judiciales para hacer frente a la misma en protección de derechos 
fundamentales de la persona, en modo alguno se ajusta a los acaecimientos que nos acucian. Ello nos interpela sobre cuán ajustado y razonable es nuestro sistema procesal. Cuán adecuado es el funcionamiento del sistema de justicia y los procesos orientados a la protección de derechos fundamentales amenazados por eventos de esta naturaleza u otros, requiriéndose de formas más eficaces de intervención.

Podemos interrogarnos hasta qué punto estructuralmente las vías o herramientas a ser utilizadas llevan en sí el germen de la "ineficacia" para la protección de los derechos. Esta es una gran oportunidad para encarar una actividad de diagnóstico y proyección de cambios al sistema en todo aquello que mejore la protección de los derechos y de las garantías.

Para ello y parangonando lo realizado por el gobierno nacional en la lucha contra el COVID-19, es necesario involucrar a los principales referentes de la ciencia del derecho y de la academia relacionados con el tema, a los órganos del sistema, a los operadores del derecho y a las organizaciones que los nuclean, para trabajar en un proyecto de adecuación del sistema de justicia y su legislación adecuada a las realidades del siglo XXI. 